\title{
Transient global amnesia and hippocampal foci of restricted diffusion
}

\author{
Carlo Augusto Mallio, ${ }^{1}$ Giovanni Assenza, ${ }^{2}$ Filomena Occhicone, ${ }^{3}$ Yuri Errante, ${ }^{1}$ \\ Bruno Beomonte Zobel, ${ }^{1}$ Carlo Cosimo Quattrocchi ${ }^{1}$
}

${ }^{1}$ Diagnostic Imaging, CIRCenter for Integrated Research in Biomedicine and

Bioengineering, University Campus Bio-Medico, Rome, Italy

${ }^{2}$ Neurology, CIR-Center for Integrated Research in Biomedicine and Bioengineering, University Campus Bio-Medico, Rome, Italy

${ }^{3}$ Department of Radiology, Fondazione San Raffaele, Cassino (FR), Italy

\section{Correspondence to} Dr Carlo Augusto Mallio, c.mallio@unicampus.it
To cite: Mallio $C A$, Assenza G, Occhicone F, et al. BMJ Case Rep Published online: [please include Day Month Year] doi:10.1136/bcr-2013010154

\section{DESCRIPTION}

A 63-year-old man was admitted owing to the onset upon awakening of anterograde amnesia and spatiotemporal disorientation accompanied by repetitive questioning. No disturbances of consciousness and self-awareness or others focal neurological symptoms were found. The EEG examination was normal.

The patient had no medical history for neurocardiovascular risk factors. The symptoms resolved spontaneously within $24 \mathrm{~h}$, with no persistent neurological impairment.

A brain MRI examination, performed $48 \mathrm{~h}$ after the onset, showed bilateral hippocampal restricted diffusion foci with low apparent diffusion coefficient (figure 1A,B); no significant white-matter hyperintensities, lacunes or chronic infarcts were detected. Brain MRI angiography was not performed.

Transient global amnesia (TGA) is a syndrome characterised by sudden anterograde memory impairment, usually associated with spontaneous remission within 24 h. $^{12}$ In such cases, amnesic gap may persist after $24 \mathrm{~h}$.

Several factors have been proposed to explain the pathophysiology of TGA such as emotional stress, arterial thromboembolism, psychological disturbances, migraine, cerebral small-vessel disease, Valsalva-like manoeuvres and jugular vein incompetency; however, the exact pathophysiology of TGA is still not completely understood. ${ }^{12}$

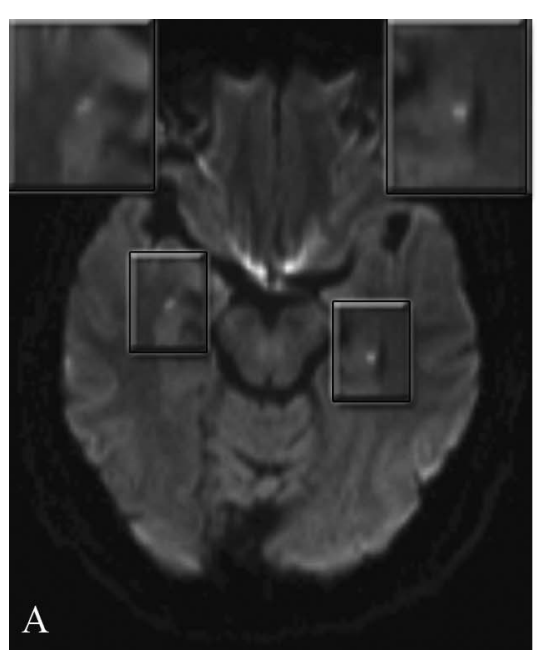
logical abnormalities or neuroactive drugs and no

Although the diagnosis of TGA is mainly clinical, brain MRI study, besides to rule out other diagnoses, enables to confirm diagnosis by detecting hippocampal restricted diffusion focal lesions. ${ }^{1}{ }^{2}$ Hippocampal signal changes are found in 11-85\% of the patients, according to the MRI parameters and to the time elapsed from the onset (maximum detection rate at $48-72 \mathrm{~h})^{2}$

\section{Learning points}

- Transient global amnesia is a syndrome characterised by sudden anterograde memory impairment with spontaneous remission within $24 \mathrm{~h}$.

- The diagnosis of transient global amnesia is clinical; however, brain MRI study enables to rule out other diagnoses and to confirm the diagnosis by detecting hippocampal restricted diffusion focal lesions.

- The maximum detection rate of hippocampal lesions on diffusion-weighted sequences is at 48-72 $\mathrm{h}$ from the onset of symptoms.

Contributors CAM and CCQ are the guarantors for the manuscript. All the authors contributed equally in the conception of the manuscript, design, acquisition of data or analysis and interpretation of data. All the authors were involved in drafting the

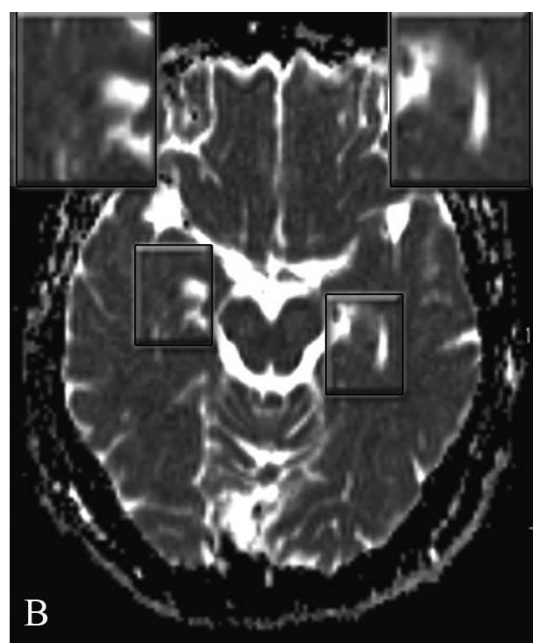

Figure 1 Bilateral hippocampal MRI signal changes: axial diffusion tensor imaging obtained by a 12-direction, single-shot, spin-echo echo-planar sequence (A) and apparent diffusion coefficient map (B). Focal areas of restricted diffusion with low apparent diffusion coefficient are shown within the right hippocampus head/body and the left hippocampus body/tail. 
manuscript, revising the manuscript for intellectual content. All the authors contributed by conducting literature search, and editing the manuscript. All the authors approved the final version of the manuscript.

\section{Competing interests None.}

Patient consent Obtained.

Provenance and peer review Not commissioned; externally peer reviewed.

\section{REFERENCES}

1 Enzinger C, Thimary F, Kapeller $\mathrm{P}$, et al. Transient global amnesia: diffusion-weighted imaging lesions and cerebrovascular disease. Stroke 2008;39:2219-25.

2 Bartsch T, Deuschl G. Transient global amnesia: functional anatomy and clinical implications. Lancet Neurol 2010;9:205-14.

Copyright 2013 BMJ Publishing Group. All rights reserved. For permission to reuse any of this content visit http://group.bmj.com/group/rights-licensing/permissions.

BMJ Case Report Fellows may re-use this article for personal use and teaching without any further permission.

Become a Fellow of BMJ Case Reports today and you can:

- Submit as many cases as you like

- Enjoy fast sympathetic peer review and rapid publication of accepted articles

- Access all the published articles

- Re-use any of the published material for personal use and teaching without further permission

For information on Institutional Fellowships contact consortiasales@bmjgroup.com

Visit casereports.bmj.com for more articles like this and to become a Fellow 